\title{
Complete plastid genome sequences of two species of the Neotropical genus Brunellia (Brunelliaceae)
}

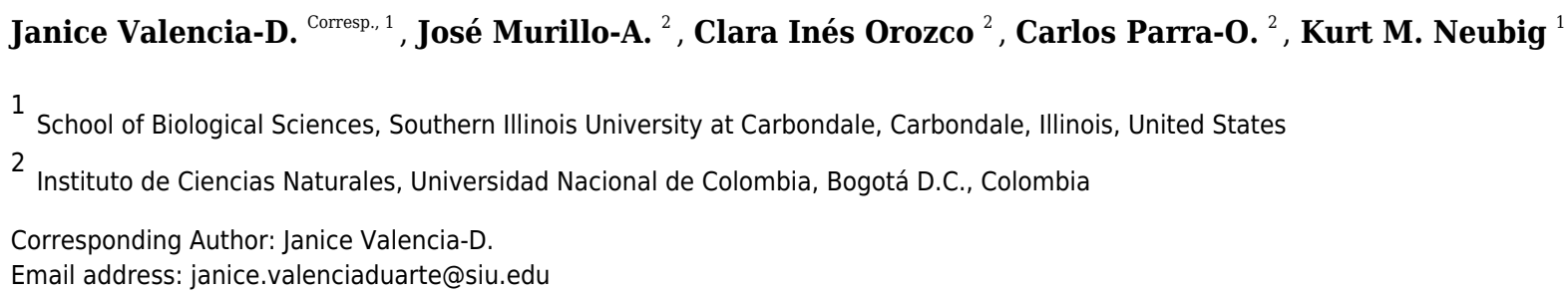

Here we present the first two complete plastid genomes for Brunelliaceae, a Neotropical family with a single genus, Brunellia. We surveyed the entire plastid genome in order to find variable cpDNA regions for further phylogenetic analyses across the family. We sampled morphologically different species, $B$. antioquensis and $B$. trianae, and found that the plastid genomes are 157,685 and 157,775 bp in length and display the typical quadripartite structure found in angiosperms. Despite the clear morphological distinction between both species, the molecular data show a very low level of divergence. The amount of nucleotide substitutions per site is one of the lowest reported to date among published congeneric studies $(\pi=0.00025)$. Plastid genomes have gene order and content coincident with other COM (Celastrales, Oxalidales, Malpighiales) relatives plastid genomes. Phylogenetic analyses of selected superrosid representatives show high bootstrap support for the $((C, M) O)$ topology. The $\mathrm{N}$-fixing clade appears as sister group of the COM clade and Zygophyllales as the sister to the rest of the fabids group. 


\section{Complete plastid genome sequences of two species of the} 2 Neotropical genus Brunellia (Brunelliaceae)

3

4

5

6

7 8

9 Corresponding Author:

10 Janice Valencia-D. ${ }^{1}$

111125 Lincoln Dr, Carbondale, Illinois, 62901-6509, USA

12 Email address: janice.valenciaduarte@siu.edu 


\section{Complete plastid genome sequences of two species 14 of the Neotropical genus Brunellia (Brunelliaceae)}

15

16

17

18

19

20

21

22

23

24

25

26

27

28

29

30

31

32

33

34

35

36

37

38

39

40

41

42

43

44

45

46

47

48

49

50

51

Janice Valencia-D. ${ }^{1}$, José Murillo-A. $^{2}$, Clara Inés Orozco ${ }^{2}$, Carlos Parra-O. ${ }^{2}$, Kurt M. Neubig ${ }^{1}$

${ }^{1}$ School of Biological Sciences, Southern Illinois University at Carbondale, Carbondale, Illinois, United States

${ }^{2}$ Instituto de Ciencias Naturales, Universidad Nacional de Colombia, Bogotá D.C., Colombia

Corresponding Author:

Janice Valencia-D. ${ }^{1}$

1125 Lincoln Dr, Carbondale, Illinois, 62901-6509, USA

Email address: janice.valenciaduarte@siu.edu

\section{Abstract}

Here we present the first two complete plastid genomes for Brunelliaceae, a Neotropical family with a single genus, Brunellia. We surveyed the entire plastid genome in order to find variable cpDNA regions for further phylogenetic analyses across the family. We sampled morphologically different species, B. antioquensis and B. trianae, and found that the plastid genomes are 157,685 and 157,775 bp in length and display the typical quadripartite structure found in angiosperms. Despite the clear morphological distinction between both species, the molecular data show a very low level of divergence. The amount of nucleotide substitutions per site is one of the lowest reported to date among published congeneric studies $(\pi=0.00025)$. Plastid genomes have gene order and content coincident with other COM (Celastrales, Oxalidales, Malpighiales) relatives plastid genomes. Phylogenetic analyses of selected superrosid representatives show high bootstrap support for the $((\mathrm{C}, \mathrm{M}) \mathrm{O})$ topology. The $\mathrm{N}$-fixing clade appears as sister group of the COM clade and Zygophyllales as the sister to the rest of the fabids group.

\section{Introduction}

Brunellia Ruiz \& Pav., with about 60 species, is the only genus within the Neotropical family Brunelliaceae Engl. Its range of distribution is from southern Mexico to Bolivia, and a single species reaches the Greater Antilles (Orozco et al., 2017). They are evergreen trees, some of which can reach $40 \mathrm{~m}$ in height and $1 \mathrm{~m}$ DBH in high mountain forests, or grow less than $10 \mathrm{~m}$ high at over 3,600 m of elevation (Cuatrecasas, 1970). They are also important elements of the Andean ecosystems where they have diversified, and comprise part of the high endemism of these zones (Orozco, 2001). The narrow range of distribution of the vast majority of the species 
52 make Brunellia an interesting group to study from phylogenetic and biogeographical

53

54

55

56

57

58

59

60

61

62

63

64

65

66

67

68

69

70

71

72

73

74

75

76

77

78

79

80

81

82

83

84

85

86

87

88

89

90

91

perspectives.

Brunelliaceae belong to the order Oxalidales in a clade formed with Cephalotaceae, Cunoniaceae and Elaeocarpaceae (Zhang \& Simmons, 2006; Soltis et al., 2011; Heibl \& Renner, 2012; Sun et al., 2016a; Li et al., 2019). Oxalidales belong to the commonly called 'COM clade' together with Celastrales and Malpighiales (Matthews \& Endress, 2006), and it has been broadly recognized as monophyletic based on plastid data (but see (Zhao et al., 2016; Zeng et al., 2017; Leebens-Mack et al., 2019)). However, despite support for monophyly of each of these three orders, there is still some controversy regarding the relationships among them.

For Brunelliaceae, the first phylogenetic analysis was made by Orozco (2001) based on morphological characters. In that study, Brunellia was recognized as monophyletic with five morphological characters as synapomorphies. Orozco (2001) proposed five sections for the genus, but the phylogenetic tree had poor resolution and low support. A phylogenetic analysis of Brunellia using molecular characters, both from nuclear and plastid DNA is currently ongoing (Murillo et al. in prep.). In a preliminary survey, plastid DNA regions (atpB-matK, $n d h F, p s a B-$ rps 14, psaI-accD, psbJ-petA, psbA-trnH, rbcL, trnS-trnG) were used, but they showed low sequence variation, making them unsuitable for resolving relationships within this genus.

With the purpose of identifying variable cpDNA regions, we surveyed the entire plastid genome of two morphologically different species, Brunellia antioquensis (Cuatrec.) Cuatrec. and $B$. trianae Cuatrec., which belong to the biggest sections in the genus, Sect. Brunellia and Sect. Simplicifolia, respectively. Brunellia antioquensis has an ochraceous to fulvous pubescence, stipules 3-5 mm long, compound leaves and fruits with U-shaped endocarp, whereas B. trianae has an appressed, lanate to arachnoid, ochraceous indument, stipules 0.5-2 $\mathrm{mm}$ long, simple leaves and fruits with boat-shaped endocarp (Fig. 1).

Here we explore the variability and utility of the plastid DNA in Brunelliaceae and document for first-time complete cp-genome sequences for two species. We characterize the plastid genome of each species and compare them in terms of divergence hotspots in coding and non-coding regions. We also analyze the plastid gene organization of Brunellia and ten other COM representatives. Finally, using 75 protein-coding regions available for 41 selected superrosid species; we establish the phylogenetic position of Brunelliaceae and produce a hypothesis of relationships among the COM clade and related orders.

\section{Materials \& Methods}

\section{DNA sampling, extraction and sequencing}

The samples used in this study were collected under the institutional Universidad Nacional de Colombia collection permit (Number: 0255 March 2014). Collections were made in Colombia in 
92 Cerro del Padre Amaya, Antioquia department, rural areas of Medellín, in October 2012 (B.

93 antioquensis C.I. Orozco 4001, B. trianae C.I. Orozco 4015). Sections of leaves were dried on

94 silica gel. Vouchers specimens of both collections were deposited at the Herbario Nacional

95 Colombiano (COL). These species belong to two different clades that were identified using ITS

96 and ETS regions (Murillo et al. pers. obs.).

97

98 DNA was extracted using a CTAB method (Doyle \& Doyle, 1987), followed by a silica

99 purification column step and elution in Tris-EDTA (Neubig et al., 2014). DNA samples were

100 adjusted to $50 \mathrm{ng} / \mu \mathrm{L}$ to be sheared to fragments of approximately $500 \mathrm{bp}$. Library preparation,

101 barcoding and sequencing on an Illumina HiSeqX were conducted at Rapid Genomics LLC

102 (Gainesville, FL, USA).

103

104

105

\section{Plastid genome assembly and annotation}

106

Sequencing process produced, on average, $7.5 \mathrm{~Gb}(\mathrm{~s} . \mathrm{d} .=0.2 \mathrm{~Gb}$ ) reads per sample. Paired-end

107 reads were trimmed (quality at 0.05 probability) and later assembled in Geneious 10.2.3

108 (Biomatters Ltd, Auckland, New Zealand). The assembly was performed by a combination of reference and de novo assemblies using as a reference the plastid genome of Averrhoa carambola, Oxalidaceae (GenBank accession KX364202). Annotations of gene-regions and rRNAs were transferred in Geneious from Averrhoa reference. The tRNAs were annotated using tRNAscan-SE v2.0 (Lowe \& Chan, 2016) implemented in CHLOROBOX (https://chlorobox.mpimp-golm.mpg.de/geseq.html). All annotations were manually reviewed and, if necessary, edited. The circular map of the plastid genome was generated with OGDRAW (https://chlorobox.mpimp-golm.mpg.de/cite-OGDraw.html, Lohse, Drechsel, Kahlau, \& Bock, 2013) and modified manually.

116

\section{Comparison of plastid genomes of Brunellia antioquensis and B. trianae}

118 Comparisons of the boundaries between the large single-copy (LSC) and the small single-copy (SSC) regions with the inverted repeats (IRA and IRB) were performed using Unipro UGENE v1.31.0 (Okonechnikov et al., 2012). Content percentages of A, T, C, G, A/T and G/C were estimated for LSC, SSC and IR regions, and for the rRNA, tRNA, protein coding regions, intergenic regions, and introns of both species with Bioedit v7.1.11 (Hall, 1999).

123

\section{Repeated sequences}

125 Identification and location of complement, forward, palindromic, and reverse repeat sequences were conducted using REPuter program (Kurtz et al., 2001). Simple sequence repeats (SSRs) were identified using the MISA program with parameters set by default (Thiel et al., 2003).

128

\section{Comparative genome analysis}

130 We compared Brunellia plastid genomes regarding nucleotide diversity $(\pi)$, insertions/deletions (InDel) and base substitutions with the program DnaSP6 (Rozas et al., 2017). Transitions (Ts) 
132

133

134

135

136

137

138

139

140

141

142

143

144

145

146

147

148

149

150

151

152

153

154

155

156

157

158

159

160

161

162

163

164

165

166

167

168

169

170

and transversions (Tv) events were identified across all loci and for protein-coding regions, they were also classified based on the effect in the amino acid chain as synonymous (S) or nonsynonymous (N) substitutions. Furthermore, the whole plastid genome sequences of Brunellia and eight other COM clade representatives were compared using Mauve (Darling et al., 2004) and mVISTA programs (Frazer et al., 2004). The eight sequences retrieved from GenBank are listed in Table S1. Plastid sequences of Ceratopetalum apetalum, Sloanea australis and Tetraena mongolica assembled by Foster et al. (2016) were annotated using the same procedure we implemented for the Brunellia samples.

\section{Phylogenomic Analyses}

We extracted and aligned by translation the protein-coding genes of the ten COM representatives in Geneious. We added 33 superrosid representatives (Table S1) from previously published matrices by Ruhfel et al. (2014a), and pruned our data accordingly. The genes considered were atpE-F, atpH-I, ccs $, c e m A, \operatorname{clpP}, \inf A, \operatorname{mat} K, n d h A-K, \operatorname{pet} A-B, \operatorname{pet} D, \operatorname{pet} G, \operatorname{pet} L, \operatorname{pet} N, \operatorname{ps} a A-C$, psaI, psaJ, psbA-F, psbH-N, psbT, psbZ, rbcL, rpl2, rpl14, rpl16, rpl20, rpl22-23, rpl32-33, rpl36, rроA-B, rрoC1-C2, rps2-4, rps7-8, rps11-12, rps 14-16, rps18-19 and $y c f 2-4$. The accD gene alignment was removed from the final concatenated matrix due to its high variability that produced conflicts in the alignment. The $a c c D$ has been reported as missing in species of Fabaceae (Fabids) and Geraniaceae (Malvids), and in some cases it has transfer to the nucleus (Rousseau-Gueutin et al., 2013; Liu et al., 2016). Phylogenetic analyses were performed using Maximum Likelihood using IQ-Tree web server (Nguyen et al., 2014; Trifinopoulos et al., 2016) with 1000 ultrafast bootstrap replicates (Hoang et al., 2017) and the GTR+F+R3 model selected with ModelFinder under BIC (Kalyaanamoorthy et al., 2017).

Information availability- The plastid genomes of $B$. antioquensis and $B$. trianae were prepared for submission for NCBI using GB2sequin (Lehwark \& Greiner, 2018) and are available in the GenBank portal with the numbers MN585217 and MN615725. The nucleotide alignments are available in supplemental information.

\section{Results}

\section{Plastid genome features}

A total of 73,003 for B. antioquensis and 97,054 for B. trianae paired-end reads were assembled to produce a mean coverage of $104.8 \times$ and $138.3 \times$, respectively. Plastid genome size of $B$. antioquensis and B. trianae is $157,685 \mathrm{bp}$ and $157,775 \mathrm{bp}$, respectively (Table 1) and consists of a single circular, double-stranded DNA sequence, showing the typical quadripartite structure (Fig. 2); both sequences include a pair of IR (26,376 bp in B. antioquensis and 26,389 bp in $B$. trianae), one SSC (17,538 bp in B. antioquensis and 17,542 bp in B. trianae), and one LSC (87,395 in B. antioquensis and 87,455 bp in B. trianae) (Table 1). The proportion of each region in the plastid genome for $B$. antioquensis is LSC $55.42 \%$, SSC $11.12 \%$ and IRs $33.46 \%$; for $B$.

Peer] reviewing PDF | (2019:07:39309:2:0:NEW 3 Dec 2019) 
171 trianae these percentages are quite similar (Table 1). Content percentages of $\mathrm{A}, \mathrm{T}, \mathrm{C}, \mathrm{G}, \mathrm{A} / \mathrm{T}$ and

172 G/C are similar for both species (Table 1).

173

174 Both genomes consist of 52.13-52.14\% protein-coding genes, 40.67-40.71\% intergenic regions, 175 10.32-10.33\% introns, 5.73\% rRNAs, and 1.85\% tRNAs (Table S2). Plastid genomes of

176 Brunellia species has 134 coding regions, including 38 tRNAs, 8 rRNAs, and 88 protein-coding 177 genes. Ninety-five genes are unique and 19 are duplicated in the IRs regions (Table S3); of the 17819 duplicate genes, seven are tRNAs, four are rRNAs, and seven are fully included and one 179 interrupted protein-coding genes. Coding regions are distributed as follows: LSC included 22 180 tRNAs and 59 protein-coding regions, IRs has 4 rRNAs, 7 tRNAs, and 7 protein-coding regions, 181 and SSC contains one tRNA and 11 protein-coding regions; additionally, $y c f 1$ is found between 182 IRA and SSC border region, and rps 12 appears three times (twice at the IRs and other one at 183 LSC region). Most of the protein-coding regions have one exon, 15 genes have one intron, 184 whereas clpP, rps 12, and $y c f 3$ present two introns (Table S4). Size of introns is between 544 to $1852549 \mathrm{bp}$, being trnK-UUU the longer on the whole cpDNA. Brunellia antioquensis and $B$. 186 trianae have similar IRA-SSC and SSC-IRB boundaries, but they are somewhat different by the 187 number of base pairs at the LSC-IR borders (Fig. 3).

188

189

190

191

192

193

194

195

196

197

198

199

200

201

202

203

204

205

206

207

208

209

210

\section{Repeated sequences and SSRs}

Twenty-six repeated sequences are found in the genome of $B$. antioquensis, whose lengths vary between 20 and $30 \mathrm{bp}$ (Table S5). Twelve of those sequences are located in intergenic regions. Twelve repeats are palindromic, eight are forward repeats, three are complement repeats, and three are reverse repeats. Fourteen repeats are found in the LSC, six in the SSC, and four in the IR. Number, size and locations of repeated sequences in B. trianae are different (Table S6). This species has 18-repeated sequences with a length that varies between 21 and $88 \mathrm{bp}$; ten of these repeats are located in intergenic regions. Of the 18 repeats, six are palindromic, 11 are forward repeats, and one is a complement repeat; no reverse repeats are found in the cpDNA of this species. Thirteen repeats are found in the LSC, one in the SSC, and four in the IR regions.

The numbers of SSRs are quite similar between the two Brunellia species. Brunellia antioquensis has 223 SSRs, including 124 mononucleotides (66 poly T, 56 poly A, 1 poly C, 1 poly G), 19 dinucleotides, 69 trinucleotides, seven tetranucleotides, one pentanucleotide, one hexanucleotide, one 13-nucleotide, and one 21-nucleotide. Brunellia trianae, with 225 SSRs, differs from $B$. antioquensis by the number of dinucleotides (18) and the number of poly T (69). Dinucleotide SSRs are only represented by units containing TA/AT (82.4\%) and TC/CT (17.6\%) in both species.

\section{Analysis of polymorphisms among the plastid genome sequences of Brunellia}

Brunellia antioquensis and B. trianae has very similar sequences. These species share $99.85 \%$ sequence similarity. In the analysis of the 157,844 bp aligned (gaps included), only $243 \mathrm{bp}$ are 
211 different corresponding to 204 indels and 39 nucleotide substitutions (Table S7). The nucleotide

212 variability expressed as the level of divergence among the sequences is $\pi=0.00025$. An

213 examination by sliding window of the alignment shows $\pi$ values range from 0 to 0.0067 for a

$214600 \mathrm{bp}$ gradation (Fig. 4). Hotspots correspond with the intergenic regions $r p s 2-r p o C 2$, petB-

215 ropA and $n d h F-c c s A$. The SSC has the highest amount of substitutions per site $(\pi=0.00068)$,

216 followed by the LSC ( $\pi=0.00026)$; the IRs have the lowest value with only two substitutions in

217 each $\left(\pi=7.6 \times 10^{-5}\right)$. Twenty-two transversions and 11 transitions evenly distributed among the

218 regions of the genome are found, with a ratio of 2:1 of Tv to Ts. Fourteen substitutions occur in

219 protein coding sequences of ten genes, including five transversions and nine transitions, giving a

220 ratio of 1:1.8 of Tv to Ts. Only five substitutions are synonymous, four of them due to the

221 replacement of thymine $(\mathrm{T})$ by cytosine $(\mathrm{C})$.

222

223

224

Among the sequences, two thirds of the indel events (20) involve the gain or loss of single nucleotides of adenine (A) or thymine (T), and they are associated with regions where they

225 appear repeated more than six times. Twenty-four indels are located in intergenic regions, six

226 indels in introns and one in the rpoC2 exon. This last indel creates a change in nine nucleotide

227 sites and causes three amino acid changes. The longest indel was $83 \mathrm{bp}$ long and is located in the LSC region between pet $N$ and $p s b M$.

229

230

\section{Comparison of the plastid genomes of COM clade representatives}

231

Three Locally Collinear Blocks are identified as the LSC, IR, and SSC (Fig. S1). The possible

232 lack of information of the Sloanea australis plastid genome in the regions adjacent to the LSC-

233 IR and IR-SSC junctions may be the reason why there is not one longer collinear block. This is

234 also detectable in the Mauve output as two inversions in the LSC and SSC. Those apparent

235

236

237 inversions denote a different starting point for the reported Sloanea sequence, which might be caused by a possible problem with the assembly. In the mVISTA analysis (Fig. S2), using $B$. antioquensis as a reference, there is high similarity among Brunellia and other Oxalidales plastid genomes.

239

240

\section{Phylogenomic analyses}

Seventy-five protein-coding regions were aligned in a matrix of 54,367 bp length. ML analysis

242 places Brunelliaceae in a clade with Cunoniaceae and Elaeocarpaceae, where Oxalidaceae is

243 sister to these 3 families (Fig. 5). The monophyly of the COM clade, as well as Fabids and

244 Malvids, is recovered with 100\% bootstrap support (BS). Oxalidales appear as sister group of the

245 Celastrales-Malpighiales clade with $89 \%$ BS. The sister group of the COM clade is the N-fixing

246 clade, and Zygophyllales is sister to them with 100\% BS in both cases. The Malvid clade is sister

247 to Fabids and is supported by $100 \% \mathrm{BS}$.

248

249

\section{Discussion}

250 We report the first two plastid genomes for Brunelliaceae that are added to the previously 
251

252

253

254

255

256

257

258

259

260

261

262

263

264

265

266

267

268

269

270

271

272

273

274

275

276

277

278

279

280

281

282

283

284

285

286

287

288

289

290

published data for Oxalidales: the fully annotated plastid genome of Averrhoa carambola (Jo et al., 2016), the preliminary plastid sequences of Ceratopetalum apetalum and Sloanea australis (Foster et al., 2016) and the plastid regions of Oxalis latifolia (Moore et al., 2010). Structure, organization, and AT/GC content are similar to the A. carambola, COM group, and other Eudicot plastid genomes (e.g. Ravi, Khurana, Tyagi, \& Khurana, 2008).

Although $B$. antioquiensis and B. trianae have different morphological characters in their leaves, indument and fruits, the plastid sequence of them is surprisingly similar. Brunellia trianae has a plastid genome that is only $90 \mathrm{bp}$ longer than $B$. antioquensis (Table 1). Differences among the size of the sequences have been related to the expansion and contraction of the IR regions (Downie \& Jansen, 2015), but in Brunellia it does not seem to be the case; variations of the boundaries occur only between the LSC region and the IRs (Fig. 3), and at these boundaries the variations are small (12 to 13 nucleotides). Therefore, IR contractions or expansions do not affect the size of the genome in the two species studied. Plastid genome variation size between species is mostly explained by an indel of $88 \mathrm{bp}$ located in the LSC region (between $p s b M$ and $p e t N$ ) in B. antioquensis. Similar results were found in Tilia, another rosid with low variability among congeneric genomes (Cai et al., 2015).

Variations between $B$. antioquensis and B. trianae comprise a difference of 39 nucleotides substitutions and 204 indels. The sequences show relatively low nucleotide variability ( $\pi=0.00025)$, with IRs less variable $\left(\pi=7.6 \times 10^{-5}\right)$ as expected due to their effect in keeping the structure and stabilization of the chromosome (e.g. Sun et al., 2016; Wicke, Schneeweiss, dePamphilis, Müller, \& Quandt, 2011). The nucleotide variability found among Brunellia species is also one of the lowest reported. In general, the $\pi$ values in trees tend to be lower than in herbs; for example, in trees: Machilus ( $\pi=0.00154$, Song et al., 2015) and Juglans ( $\pi=0.00219$, Hu, Woeste, \& Zhao, 2017); in herbs: Nicotiana ( $\pi=0.00321$, Asaf et al., 2016), Aconitum ( $\pi=0.00549$, Kong, Liu, Yao, \& Gong, 2017) and Papaver ( $\pi=0.00895$, Zhou et al., 2018).

Discrepancies in the rate of molecular substitutions can be explained by variations of generation time, size and habit, the age of the clade, and molecular mechanisms of DNA repair, among others (e.g. Lanfear et al., 2013; Smith \& Donoghue, 2008). In the case of Brunellia trees, likely rapid and recent diversification in the last 5 mya (Murillo et al. in prep.) might explain a $\pi$ value ten times smaller than the one recorded for other trees. High morphological diversity and low molecular divergence has also been found in other Andean clades that speciated during the PlioPleistocene (e. g. Hughes \& Eastwood, 2006; Nürk, Scheriau, \& Madriñán, 2013).

Previously, we analyzed eight plastid regions and found low variability and no phylogenetic signal (Murillo et al. in prep.). This fact is not surprising, given the overall low variability in the complete plastid genome. In this study we found three variable intergenic regions ( $r p s 2-r p o C 2$, petB-ropA and $n d h F-c c s A, \pi=0.005-0.0067)$; although with low sequence divergence, they could represent the most variable plastid regions useful in phylogenetic analysis of Brunellia. 
291

292

293

294

295

296

297

298

299

300

301

302

303

304

305

306

307

308

309

310

311

312

313

314

315

316

317

318

319

320

321

322

323

324

325

326

327

328

329

The use of either complete plastid genomes or many coding regions have proved to increase the resolution and support of the relationships in phylogenetic analyses (e.g. Jansen et al., 2007; Moore, Bell, Soltis, \& Soltis, 2007). In our analyses, the inclusion of Brunellia sequences, the data produced by Foster et al. (2016; Sloanea australis and Ceratophyllum apetalum), and genome published by Jo et al. (2016; Averrhoa carambola), Gu, Tembrock, Zheng, \& Wu (2018; Catha edulis) and Xia et al. (2018; Parnassia brevistyla) gave us the opportunity to improve the dataset for Oxalidales and Celastrales in terms of amount of characters and taxon sampling. Despite the possible assembly issues in the $S$. australis plastid genome, the coding regions placed it in the expected phylogenetic position, so we decided to include it in the complete analysis. To date, plastid sequences of Averrhoa and Oxalis were the only ones used to represent the whole order (Sun et al., 2015; Jo et al., 2016).

The phylogenetic reconstruction placed Brunelliaceae in the clade Oxalidales and sister to the clade Cunoniaceae-Elaeocarpaceae with $76 \%$ BS, which is congruent with Soltis et al. (2011). These relationships disagree with Zhang \& Simmons (2006) in which Brunelliaceae is sister to Cunoniaceae. Sun et al. (2016) and Heibl \& Renner (2012) include in their analyses Cephalotaceae (not present in our sampling) and do not recover the clade CunoniaceaeElaeocarpaceae. In these, Brunelliaceae is sister to Cephalotaceae, this clade sister to Elaeocarpaceae, and Cunoniaceae sister to all three. Further work is needed with a wider sampling to disentangle the phylogenetic relationships among these four families.

Our results depict that the COM clade is monophyletic with $100 \% \mathrm{BS}$, which is consistent with many phylogenetic analyses from plastid data (see Table S8). However, nuclear data sets have not shown this monophyly, and support the relationships (C,M)(O,Malvids p.p.) (Zhao et al., 2016; Zeng et al., 2017; Leebens-Mack et al., 2019). Inside the COM clade, the relationships among the three orders have been conflicting. Phylogenetic analyses that support each one of the three possible topologies among the orders are compiled in Table S8. We found that Celastrales and Malpighiales form a clade with $89 \%$ BS making the $((\mathrm{C}, \mathrm{M}) \mathrm{O})$ topology the most likely according to our data. These relationships had been found by Li et al. (2019) using 80 plastid genes, by Cauz-Santos et al. (2017) using 43 plastid coding regions, by Moore et al. (2011) using all IR data, and by Zhang \& Simmons (2006), Soltis, Gitzendanner \& Soltis (2007) and Burleigh et al. (2009) using few plastid and nuclear genes. The $(C(O, M))$ topology was found by Ruhfel et al. (2014b) using 1,2 codon positions and Wu et al. (2014) using all three, however both show low bootstrap support. The third possible topology $((\mathrm{C}, \mathrm{O}) \mathrm{M})$ has been also recovered using plastid coding regions (Ruhfel et al., 2014b; Sun et al., 2015), but the change in the taxon sampling leads to the ((C,M)O) topology (Fig. 5). Therefore, conflicting results with other plastid-based phylogenies may be caused by the small sampling of Celastrales (i.e. Euonymus americanus) and Oxalidales (i.e. Oxalis latifolia or Averrhoa carambola) in the analyses (Ruhfel

Peer) reviewing PDF | (2019:07:39309:2:0:NEW 3 Dec 2019) 
330

331

332

333

334

335

336

337

338

339

340

341

342

343

344

345

346

347

348

349

350

351

352

353

354

355

356

357

358

359

360

361

362

363

364

365

366

367

368

et al., 2014b; Wu et al., 2014; Sun et al., 2015; Jo et al., 2016) or by the use of an amino acid dataset (Ruhfel et al., 2014b; Gitzendanner et al., 2018).

The phylogenetic analysis shows that the $\mathrm{N}$-fixing clade is sister to the COM clade with $100 \%$ BS. This relationship has been found in other studies based on plastid data (Sun et al. 2015, Table 1). However, when nuclear and mitochondrial data are analyzed the COM clade is sister to Malvids or even not monophyletic. Sun et al. (2015) developed a hypothesis of the possible origin of the COM clade genome by the action of introgression and hybridization processes from both malvid and fabid ancestors. This scenario, in which the mitochondrial and most of the nuclear genomes would have their origin from a Malvid ancestor, and the plastid genome from a Fabid ancestor, would explain the observed discrepancies in the phylogenies (Sun et al., 2015). Therefore, deep analyses based on molecular data from all three genomes will give us a better understanding of the evolutionary processes within the diversity of rosids.

Based on our analysis of plastid data, the Fabid clade appears monophyletic (including Zygophyllales) with $100 \%$ BS. Zygophyllales is sister to the rest of Fabids, as has been previously found with large datasets (e.g. Soltis et al., 2011; M. Sun et al., 2015), but further analysis including more representatives of Zygophyllales is necessary because other studies have found the order sister to Malvids (Zhao et al., 2016) or in an uncertain position (Ruhfel et al., 2014b).

\section{Conclusions}

Assemblies of complete plastid genomes have proved to be useful for the identification of variable sites that can work as barcodes for specific groups; however, Brunellia sequences do not show high levels of variation and are not particularly useful for this purpose. Our results agree with previous analyses in which we tested eight plastid regions for phylogenetic purposes. Here, we present for the first time, plastid genomes for Brunelliaceae. We analyzed the genomes of two species to look for regions with high variability, but we found a very low level of nucleotide diversity. The three main hotspots identified among them were mainly composed by indel regions, with some potential in further systematic analyses. Phylogenetic analyses of Brunellia plastid regions plus another 41 superrosid representatives corroborate the placement of the family in Oxalidales, and as sister group of a clade formed by Cunoniaceae and Elaeocarpaceae. Our data also support Oxalidales as sister of the Celastrales-Malpighiales clade. This topology disagrees with most common scenario of Celastrales and Oxalidales as sister groups, however, all three possible topologies have been found with both small and large datasets. Possible causes of incongruence may be related to taxon sampling and the lack of information for many species in the less diverse orders, as Celastrales and Oxalidales, which tend to be poorly represented in the phylogenies. Future studies focused on the COM group should include a better representation 
369

370

371

372

373

374

375

376

377

378

379

380

381

382

383

384

385

386

387

388

389

390

391

392

393

394

395

396

397

398

399

400

401

402

403

404

405

406

407

408

409

of families and genera in order to understand other evolutionary trends in this relatively recently recognized clade.

\section{Acknowledgements}

We would like to thank Jorge Vélez and Juan Pablo Tobón at the Universidad Nacional de Colombia - sede Medellín, for assisting with fieldwork.

\section{References}

Asaf S, Khan AL, Khan AR, Waqas M, Kang S-M, Khan MA, Lee S-M, Lee I-J. 2016. Complete chloroplast genome of Nicotiana otophora and its comparison with related species. Frontiers in Plant Science 7. DOI: 10.3389/fpls.2016.00843.

Burleigh JG, Hilu KW, Soltis DE. 2009. Inferring phylogenies with incomplete data sets: a 5-gene, 567taxon analysis of angiosperms. BMC Evolutionary Biology 9:61. DOI: 10.1186/1471-2148-9-61.

Cai J, Ma P-F, Li H-T, Li D-Z. 2015. Complete plastid genome sequencing of four Tilia species (Malvaceae): a comparative analysis and phylogenetic implications. PLoS One 10:e142705.

Cauz-Santos LA, Munhoz CF, Rodde N, Cauet S, Santos AA, Penha HA, Dornelas MC, Varani AM, Oliveira GCX, Bergès H, Vieira MLC. 2017. The chloroplast genome of Passiflora edulis (Passifloraceae) assembled from long sequence reads: Structural organization and phylogenomic studies in Malpighiales. Frontiers in Plant Science 8. DOI: 10.3389/fpls.2017.00334.

Cuatrecasas J. 1970. Brunelliaceae. Flora Neotropica 2:1-188.

Darling ACE, Mau B, Blattner FR, Perna NT. 2004. Mauve: multiple alignment of conserved genomic sequence with rearrangements. Genome research 14:1394-1403. DOI: 10.1101/gr.2289704.

Downie SR, Jansen RK. 2015. A comparative analysis of whole plastid genomes from the Apiales: expansion and contraction of the inverted repeat, mitochondrial to plastid transfer of DNA, and identification of highly divergent noncoding regions. Systematic Botany 40:336-351.

Doyle J, Doyle J. 1987. Genomic plant DNA preparation from fresh tissue-CTAB method. Phytochem Bull 19:11-15.

Foster CSP, Sauquet H, van der Merwe M, McPherson H, Rossetto M, Ho SYW. 2016. Evaluating the impact of genomic data and priors on bayesian estimates of the Angiosperm evolutionary timescale. Systematic Biology:syw086. DOI: 10.1093/sysbio/syw086.

Frazer KA, Pachter L, Poliakov A, Rubin EM, Dubchak I. 2004. VISTA: computational tools for comparative genomics. Nucleic Acids Research 32:W273-W279.

Gitzendanner MA, Soltis PS, Wong GK, Ruhfel BR, Soltis DE. 2018. Plastid phylogenomic analysis of green plants: a billion years of evolutionary history. American Journal of Botany 105:291-301.

Gu C, Tembrock L, Zheng S, Wu Z. 2018. The complete chloroplast genome of Catha edulis: A comparative analysis of genome features with related species. International Journal of Molecular Sciences 19:525. DOI: 10.3390/ijms19020525.

Hall TA. 1999. BioEdit: a user-friendly biological sequence alignment editor and analysis program for Windows 95/98/NT. In: [London]: Information Retrieval Ltd., c1979-c2000., 95-98. 
410

411

412

413

414

415

416

417

418

419

420

421

422

423

424

425

426

427

428

429

430

431

432

433

434

435

436

437

438

439

440

441

442

443

444

445

446

447

448

449

450

451

452

453

Heibl C, Renner SS. 2012. Distribution models and a dated phylogeny for Chilean Oxalis species reveal occupation of new habitats by different lineages, not rapid adaptive radiation. Systematic Biology 61:823-834.

Hoang DT, Chernomor O, von Haeseler A, Minh BQ, Le SV. 2017. UFBoot2: Improving the Ultrafast Bootstrap Approximation. Molecular biology and evolution:msx281.

$\mathrm{Hu}$ Y, Woeste KE, Zhao P. 2017. Completion of the chloroplast genomes of five Chinese Juglans and their contribution to chloroplast phylogeny. Frontiers in Plant Science 7. DOI: 10.3389/fpls.2016.01955.

Hughes C, Eastwood R. 2006. Island radiation on a continental scale: Exceptional rates of plant diversification after uplift of the Andes. Proceedings of the National Academy of Sciences 103:10334-10339. DOI: 10.1073/pnas.0601928103.

Jansen RK, Cai Z, Raubeson LA, Daniell H, Depamphilis CW, Leebens-Mack J, Müller KF, GuisingerBellian M, Haberle RC, Hansen AK. 2007. Analysis of 81 genes from 64 plastid genomes resolves relationships in angiosperms and identifies genome-scale evolutionary patterns. Proceedings of the National Academy of Sciences 104:19369-19374.

Jo S, Kim HW, Kim YK, Cheon SH, Kim K-J. 2016. Complete plastome sequence of Averrhoa carambola L. (Oxalidaceae). Mitochondrial DNA Part B 1:609-611. DOI: 10.1080/23802359.2016.1209095.

Kalyaanamoorthy S, Minh BQ, Wong TK, von Haeseler A, Jermiin LS. 2017. ModelFinder: fast model selection for accurate phylogenetic estimates. Nature Methods.

Kong H, Liu W, Yao G, Gong W. 2017. A comparison of chloroplast genome sequences in Aconitum (Ranunculaceae): a traditional herbal medicinal genus. PeerJ 5:e4018. DOI: 10.7717/peerj.4018.

Kurtz S, Choudhuri JV, Ohlebusch E, Schleiermacher C, Stoye J, Giegerich R. 2001. REPuter: the manifold applications of repeat analysis on a genomic scale. Nucleic Acids Research 29:46334642.

Lanfear R, Ho SYW, Davies TJ, Moles AT, Aarssen L, Swenson NG, Warman L, Zanne AE, Allen AP. 2013. Taller plants have lower rates of molecular evolution. Nature Communications 4:1879. DOI: $10.1038 /$ ncomms 2836 .

Leebens-Mack JH, Barker MS, Carpenter EJ, Deyholos MK, Gitzendanner MA, Graham SW, Grosse I, Li Z, Melkonian M, Mirarab S, Porsch M, Quint M, Rensing SA, Soltis DE, Soltis PS, Stevenson DW, Ullrich KK, Wickett NJ, DeGironimo L, Edger PP, Jordon-Thaden IE, Joya S, Liu T, Melkonian B, Miles NW, Pokorny L, Quigley C, Thomas P, Villarreal JC, Augustin MM, Barrett MD, Baucom RS, Beerling DJ, Benstein RM, Biffin E, Brockington SF, Burge DO, Burris JN, Burris KP, Burtet-Sarramegna V, Caicedo AL, Cannon SB, Çebi Z, Chang Y, Chater C, Cheeseman JM, Chen T, Clarke ND, Clayton H, Covshoff S, Crandall-Stotler BJ, Cross H, dePamphilis CW, Der JP, Determann R, Dickson RC, Di Stilio VS, Ellis S, Fast E, Feja N, Field KJ, Filatov DA, Finnegan PM, Floyd SK, Fogliani B, García N, Gâteblé G, Godden GT, Goh F (Qi Y, Greiner S, Harkess A, Heaney JM, Helliwell KE, Heyduk K, Hibberd JM, Hodel RGJ, Hollingsworth PM, Johnson MTJ, Jost R, Joyce B, Kapralov MV, Kazamia E, Kellogg EA, Koch MA, Von Konrat M, Könyves K, Kutchan TM, Lam V, Larsson A, Leitch AR, Lentz R, Li F-W, Lowe AJ, Ludwig M, Manos PS, Mavrodiev E, McCormick MK, McKain M, McLellan T, McNeal JR, Miller RE, Nelson MN, Peng Y, Ralph P, Real D, Riggins CW, Ruhsam M, Sage RF, Sakai AK, Scascitella M, Schilling EE, Schlösser E-M, Sederoff H, Servick S, Sessa EB, Shaw AJ, Shaw SW, Sigel EM, Skema C, Smith AG, Smithson A, Stewart CN, Stinchcombe JR,

Peer] reviewing PDF | (2019:07:39309:2:0:NEW 3 Dec 2019) 
454

455

456

457

458

459

460

461

462

463

464

465

466

467

468

469

470

471

472

473

474

475

476

477

478

479

480

481

482

483

484

485

486

487

488

489

490

491

492

493

494

495

Szövényi P, Tate JA, Tiebel H, Trapnell D, Villegente M, Wang C-N, Weller SG, Wenzel M, Weststrand S, Westwood JH, Whigham DF, Wu S, Wulff AS, Yang Y, Zhu D, Zhuang C, Zuidof J, Chase MW, Pires JC, Rothfels CJ, Yu J, Chen C, Chen L, Cheng S, Li J, Li R, Li X, Lu H, Ou Y, Sun X, Tan X, Tang J, Tian Z, Wang F, Wang J, Wei X, Xu X, Yan Z, Yang F, Zhong X, Zhou F, Zhu Y, Zhang Y, Ayyampalayam S, Barkman TJ, Nguyen N, Matasci N, Nelson DR, Sayyari E, Wafula EK, Walls RL, Warnow T, An H, Arrigo N, Baniaga AE, Galuska S, Jorgensen SA, Kidder TI, Kong H, Lu-Irving P, Marx HE, Qi X, Reardon CR, Sutherland BL, Tiley GP, Welles SR, Yu R, Zhan S, Gramzow L, Theißen G, Wong GK-S, One Thousand Plant Transcriptomes Initiative. 2019. One thousand plant transcriptomes and the phylogenomics of green plants. Nature 574:679-685. DOI: 10.1038/s41586-019-1693-2.

Lehwark P, Greiner S. 2018. GB2sequin-A file converter preparing custom GenBank files for database submission. Genomics.

Li H-T, Yi T-S, Gao L-M, Ma P-F, Zhang T, Yang J-B, Gitzendanner MA, Fritsch PW, Cai J, Luo Y, Wang H, van der Bank M, Zhang S-D, Wang Q-F, Wang J, Zhang Z-R, Fu C-N, Yang J, Hollingsworth PM, Chase MW, Soltis DE, Soltis PS, Li D-Z. 2019. Origin of angiosperms and the puzzle of the Jurassic gap. Nature Plants 5:461-470. DOI: 10.1038/s41477-019-0421-0.

Liu T-J, Zhang C-Y, Yan H-F, Zhang L, Ge X-J, Hao G. 2016. Complete plastid genome sequence of Primula sinensis (Primulaceae): structure comparison, sequence variation and evidence for $a c c D$ transfer to nucleus. PeerJ 4:e2101. DOI: 10.7717/peerj.2101.

Lohse M, Drechsel O, Kahlau S, Bock R. 2013. OrganellarGenomeDRAW - a suite of tools for generating physical maps of plastid and mitochondrial genomes and visualizing expression data sets. Nucleic acids research 41:W575-W581.

Lowe TM, Chan PP. 2016. tRNAscan-SE On-line: integrating search and context for analysis of transfer RNA genes. Nucleic Acids Research 44:W54-W57. DOI: 10.1093/nar/gkw413.

Matthews ML, Endress PK. 2006. Floral structure and systematics in four orders of rosids, including a broad survey of floral mucilage cells. Plant Systematics and Evolution. DOI: 10.1007/s00606006-0443-8.

Moore MJ, Bell CD, Soltis PS, Soltis DE. 2007. Using plastid genome-scale data to resolve enigmatic relationships among basal angiosperms. Proceedings of the National Academy of Sciences 104:19363-19368.

Moore MJ, Hassan N, Gitzendanner MA, Bruenn RA, Croley M, Vandeventer A, Horn JW, Dhingra A, Brockington SF, Latvis M, Ramdial J, Alexandre R, Piedrahita A, Xi Z, Davis CC, Soltis PS, Soltis DE. 2011. Phylogenetic analysis of the plastid inverted repeat for 244 species: Insights into deeper-level angiosperm relationships from a long, slowly evolving sequence region. International Journal of Plant Sciences 172:541-558. DOI: 10.1086/658923.

Moore MJ, Soltis PS, Bell CD, Burleigh JG, Soltis DE. 2010. Phylogenetic analysis of 83 plastid genes further resolves the early diversification of eudicots. Proceedings of the National Academy of Sciences 107:4623-4628. DOI: 10.1073/pnas.0907801107.

Neubig KM, Whitten WM, Abbot JR, Elliott S, Soltis DE, Soltis P. 2014. Variables affecting DNA preservation in archival plant specimens. In: Applequist W, Campbell L eds. DNA Banking for the 21st Century: Proceedings of the US Workshop on DNA Banking. St. Louis, Miss: William L. Brown Center, Missouri Botanical Garden, 81-112.

Peer] reviewing PDF | (2019:07:39309:2:0:NEW 3 Dec 2019) 
496

497

498

499

500

501

502

503

504

505

506

507

508

509

510

511

512

513

514

515

516

517

518

519

520

521

522

523

524

525

526

527

528

529

530

531

532

533

534

535

536

537

538

Nguyen L-T, Schmidt HA, von Haeseler A, Minh BQ. 2014. IQ-TREE: a fast and effective stochastic algorithm for estimating maximum-likelihood phylogenies. Molecular biology and evolution 32:268-274.

Nickrent DL, Der JP, Anderson FE. 2005. Discovery of the photosynthetic relatives of the" Maltese mushroom" Cynomorium. BMC Evolutionary Biology 5:38.

Nürk NM, Scheriau C, Madriñán S. 2013. Explosive radiation in high Andean Hypericum —rates of diversification among New World lineages. Frontiers in Genetics 4. DOI: 10.3389/fgene.2013.00175.

Okonechnikov K, Golosova O, Fursov M, Ugene Team. 2012. Unipro UGENE: a unified bioinformatics toolkit. Bioinformatics 28:1166-1167.

Orozco. 2001. Evolutionary biology of Brunellia Ruiz \& Pavon (Brunelliaceae, Oxalidales). Ph.D. Dissertation. Amsterdam: Universiteit van Amsterdam.

Orozco, Perez AJ, Romoleroux K, Murillo Aldana J. 2017. The discovery of a new species of Brunellia (Brunelliaceae) with ephemeral petals from Llanganates National Park, Ecuador. Phytotaxa 311:263-269.

Ravi V, Khurana JP, Tyagi AK, Khurana P. 2008. An update on chloroplast genomes. Plant Systematics and Evolution 271:101-122. DOI: 10.1007/s00606-007-0608-0.

Rousseau-Gueutin M, Huang X, Higginson E, Ayliffe M, Day A, Timmis JN. 2013. Potential functional replacement of the plastidic acetyl-CoA carboxylase subunit $(a c c D)$ gene by recent transfers to the nucleus in some angiosperm lineages. Plant Physiology 161:1918-1929. DOI: 10.1104/pp.113.214528.

Rozas J, Ferrer-Mata A, Sánchez-DelBarrio JC, Guirao-Rico S, Librado P, Ramos-Onsins SE, SánchezGracia A. 2017. DnaSP 6: DNA sequence polymorphism analysis of large data sets. Molecular biology and evolution 34:3299-3302.

Ruhfel BR, Gitzendanner MA, Soltis PS, Soltis DE, Burleigh JG. 2014a. Data from: From algae to angiosperms-inferring the phylogeny of green plants (Viridiplantae) from 360 plastid genomes. DOI: $10.5061 /$ dryad.k1t1f.

Ruhfel BR, Gitzendanner MA, Soltis PS, Soltis DE, Burleigh JG. 2014b. From algae to angiospermsinferring the phylogeny of green plants (Viridiplantae) from 360 plastid genomes. BMC Evolutionary Biology 14:23.

Smith SA, Donoghue MJ. 2008. Rates of molecular evolution are linked to life history in flowering plants. Science 322:86-89. DOI: 10.1126/science.1163197.

Soltis DE, Gitzendanner MA, Soltis PS. 2007. A 567-taxon data set for angiosperms: the challenges posed by Bayesian analyses of large data sets. International Journal of Plant Sciences 168:137157.

Soltis DE, Smith SA, Cellinese N, Wurdack KJ, Tank DC, Brockington SF, Refulio-Rodriguez NF, Walker JB, Moore MJ, Carlsward BS, Bell CD, Latvis M, Crawley S, Black C, Diouf D, Xi Z, Rushworth CA, Gitzendanner MA, Sytsma KJ, Qiu Y-L, Hilu KW, Davis CC, Sanderson MJ, Beaman RS, Olmstead RG, Judd WS, Donoghue MJ, Soltis PS. 2011. Angiosperm phylogeny: 17 genes, 640 taxa. American Journal of Botany 98:704-730. DOI: 10.3732/ajb.1000404.

Song Y, Dong W, Liu B, Xu C, Yao X, Gao J, Corlett RT. 2015. Comparative analysis of complete chloroplast genome sequences of two tropical trees Machilus yunnanensis and Machilus balansae in the family Lauraceae. Frontiers in Plant Science 6. DOI: 10.3389/fpls.2015.00662.

Peer] reviewing PDF | (2019:07:39309:2:0:NEW 3 Dec 2019) 
539

540

541

542

543

544

545

546

547

548

549

550

551

552

553

554

555

556

557

558

559

560

561

562

563

564

565

566

567

568

569

570

571

572

573

574

575

576

Sun Y, Moore MJ, Zhang S, Soltis PS, Soltis DE, Zhao T, Meng A, Li X, Li J, Wang H. 2016a. Phylogenomic and structural analyses of 18 complete plastomes across nearly all families of early-diverging eudicots, including an angiosperm-wide analysis of IR gene content evolution. Molecular Phylogenetics and Evolution 96:93-101. DOI: 10.1016/j.ympev.2015.12.006.

Sun M, Naeem R, Su J-X, Cao Z-Y, Burleigh JG, Soltis PS, Soltis DE, Chen Z-D. 2016b. Phylogeny of the Rosidae: A dense taxon sampling analysis: Phylogeny of the Rosidae. Journal of Systematics and Evolution 54:363-391. DOI: 10.1111/jse.12211.

Sun M, Soltis DE, Soltis PS, Zhu X, Burleigh JG, Chen Z. 2015. Deep phylogenetic incongruence in the angiosperm clade Rosidae. Molecular Phylogenetics and Evolution 83:156-166. DOI: 10.1016/j.ympev.2014.11.003.

Thiel T, Michalek W, Varshney R, Graner A. 2003. Exploiting EST databases for the development and characterization of gene-derived SSR-markers in barley (Hordeum vulgare L.). Theoretical and Applied Genetics 106:411-422.

Trifinopoulos J, Nguyen L-T, von Haeseler A, Minh BQ. 2016. W-IQ-TREE: a fast online phylogenetic tool for maximum likelihood analysis. Nucleic acids research 44:W232-W235.

Wicke S, Schneeweiss GM, dePamphilis CW, Müller KF, Quandt D. 2011. The evolution of the plastid chromosome in land plants: gene content, gene order, gene function. Plant Molecular Biology 76:273-297. DOI: 10.1007/s11103-011-9762-4.

Wu Z, Gui S, Quan Z, Pan L, Wang S, Ke W, Liang D, Ding Y. 2014. A precise chloroplast genome of Nelumbo nucifera (Nelumbonaceae) evaluated with Sanger, Illumina MiSeq, and PacBio RS II sequencing platforms: insight into the plastid evolution of basal eudicots. BMC Plant Biology 14:289.

Xia M, Zhang F, Rao H, Chi X, Khan G, Zhang Y, Yu J, Chen S. 2018. Complete chloroplast genome sequence of Parnassia brevistyla (Celastraceae) and phylogenetic analysis with related species. Mitochondrial DNA Part B 3:1187-1188. DOI: 10.1080/23802359.2018.1524725.

Zeng L, Zhang N, Zhang Q, Endress PK, Huang J, Ma H. 2017. Resolution of deep eudicot phylogeny and their temporal diversification using nuclear genes from transcriptomic and genomic datasets. New Phytologist 214:1338-1354. DOI: 10.1111/nph.14503.

Zhang L-B, Simmons MP. 2006. Phylogeny and delimitation of the Celastrales inferred from nuclear and plastid genes. Systematic Botany 31:122-137. DOI: 10.1600/036364406775971778.

Zhao L, Li X, Zhang N, Zhang S-D, Yi T-S, Ma H, Guo Z-H, Li D-Z. 2016. Phylogenomic analyses of large-scale nuclear genes provide new insights into the evolutionary relationships within the rosids. Molecular Phylogenetics and Evolution 105:166-176. DOI: 10.1016/j.ympev.2016.06.007.

Zhou J, Cui Y, Chen X, Li Y, Xu Z, Duan B, Li Y, Song J, Yao H. 2018. Complete chloroplast genomes of Papaver rhoeas and Papaver orientale: Molecular structures, comparative analysis, and phylogenetic analysis. Molecules 23:437. DOI: 10.3390/molecules23020437.

Peer] reviewing PDF | (2019:07:39309:2:0:NEW 3 Dec 2019) 


\section{Figure 1}

Brunellia antioquensis (Cuatrec.) Cuatrec. and B. trianae Cuatrec.

Brunellia antioquensis (A) Habit. (B) twig with infructescences. (C) young leaflets and stipels.

Brunellia trianae (D) twig with adult leaves and vegetative buds. (E) twig with

infructescences. [(A)-(C) from Orozco et al. 4021 (COL), (D)-(E) from Orozco et al. 4019

$(\mathrm{COL})]$. Scale for $(A)=2 \mathrm{~m},(B)=2 \mathrm{~cm},(C)=1 \mathrm{~cm},(D)-(E)=2 \mathrm{~cm}$. Photos by Clara I. Orozco. 

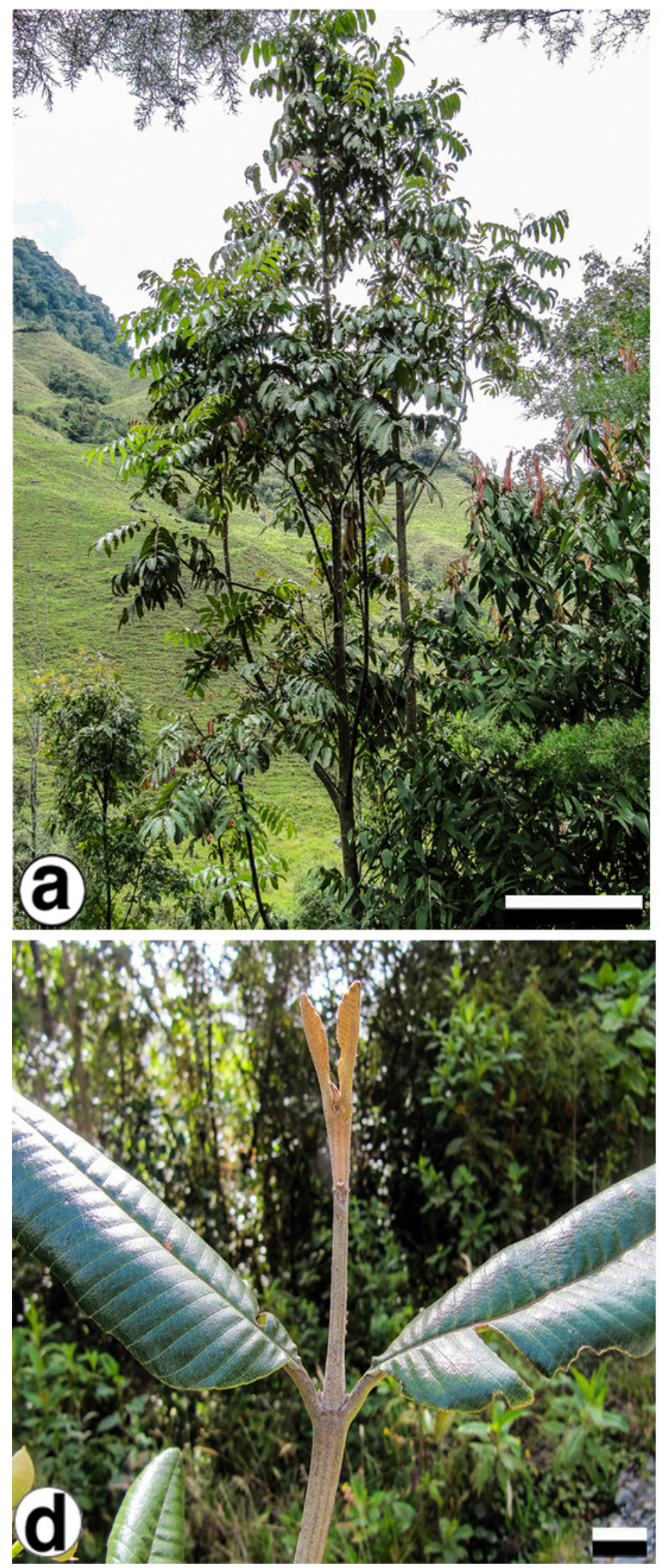
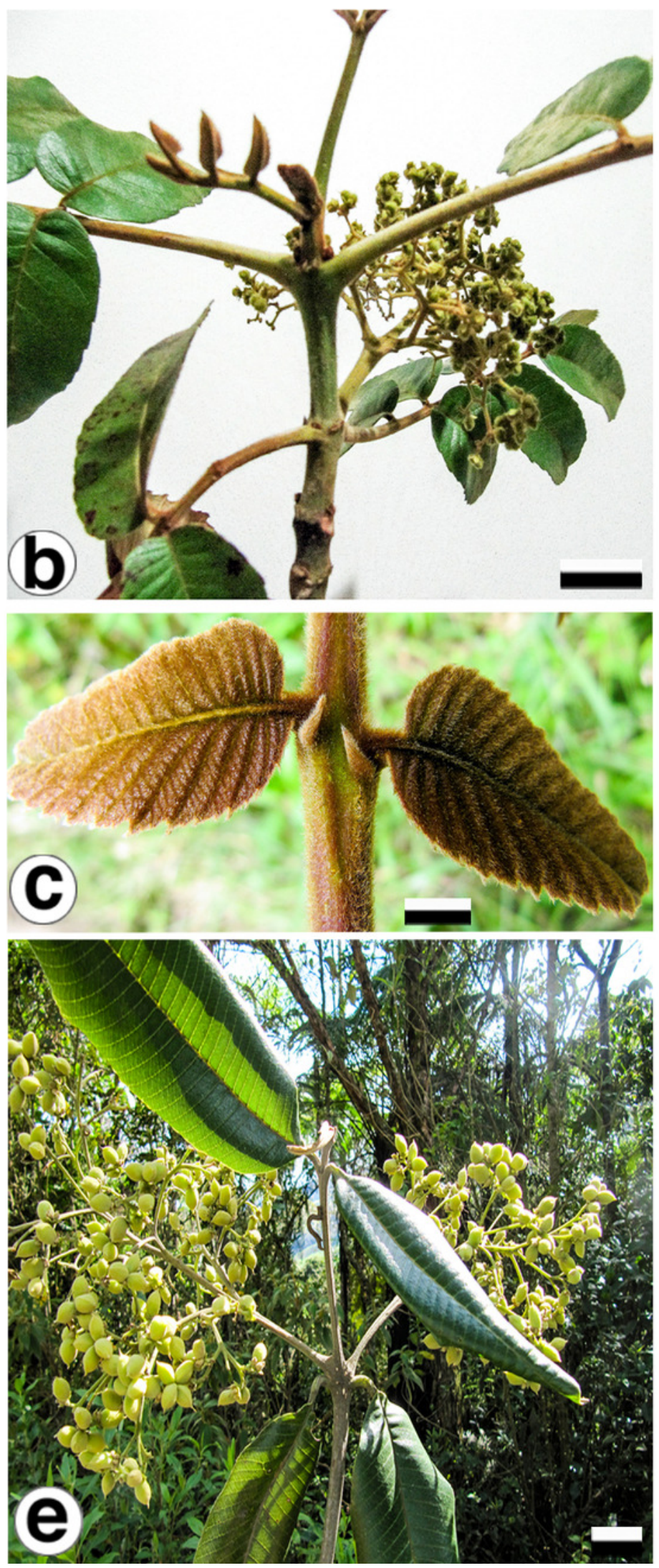
Figure 2

Gene map of the plastid genome of Brunellia antioquensis and B. trianae.

Genes placed inside of the outer circle are transcribed in counterclockwise direction whereas genes outside are transcribed in the clockwise direction. Colors refer to genes from different functional groups. The lighter grey area in the inner circle indicates AT content, while the darker grey area indicates GC content. 


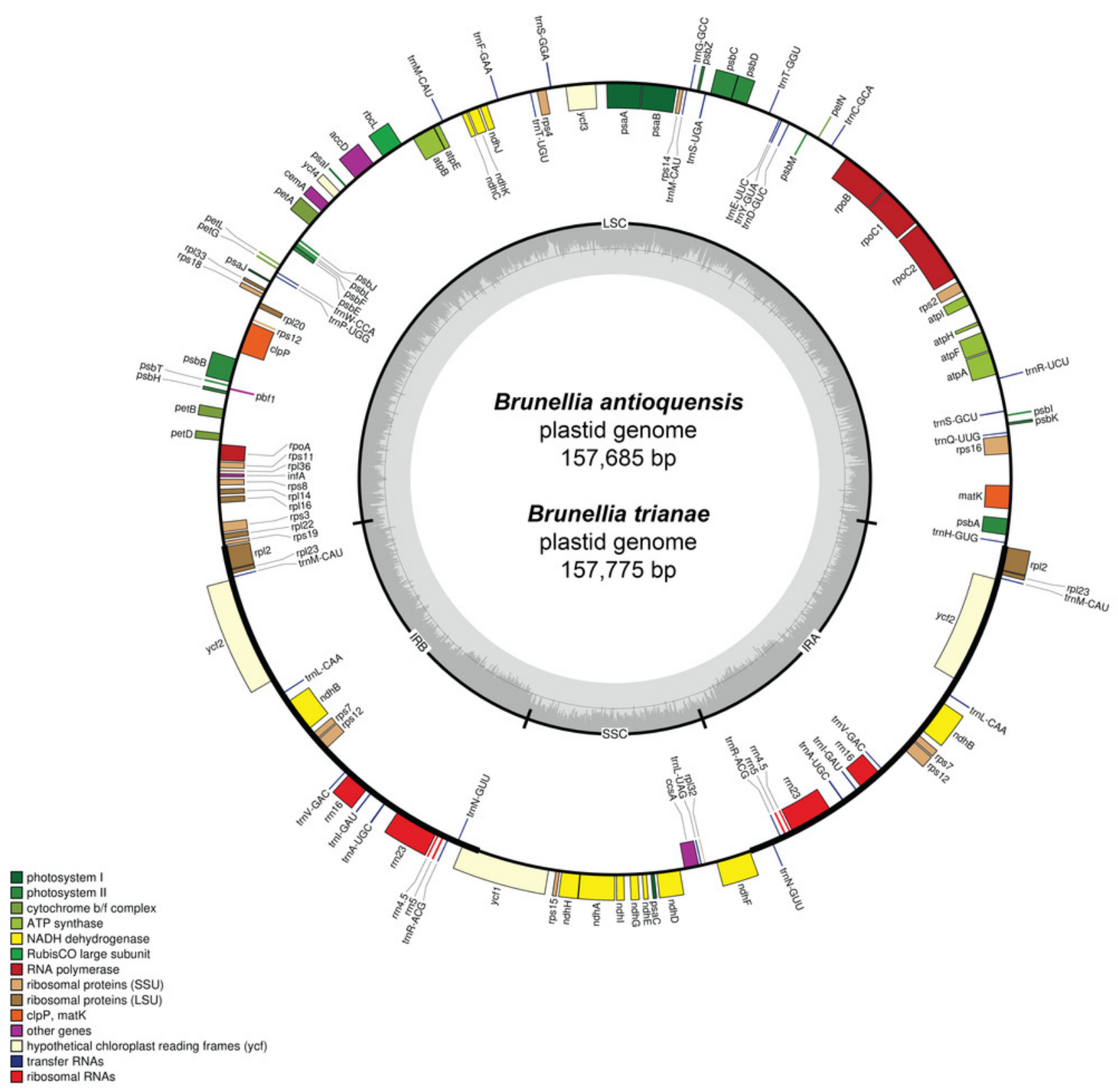


Figure 3

Boundaries among different plastid regions.

(A) Brunellia antioquensis. (B) B. trianae. Apparent size of each region, gene, and distance in bp at ends (not to scale).
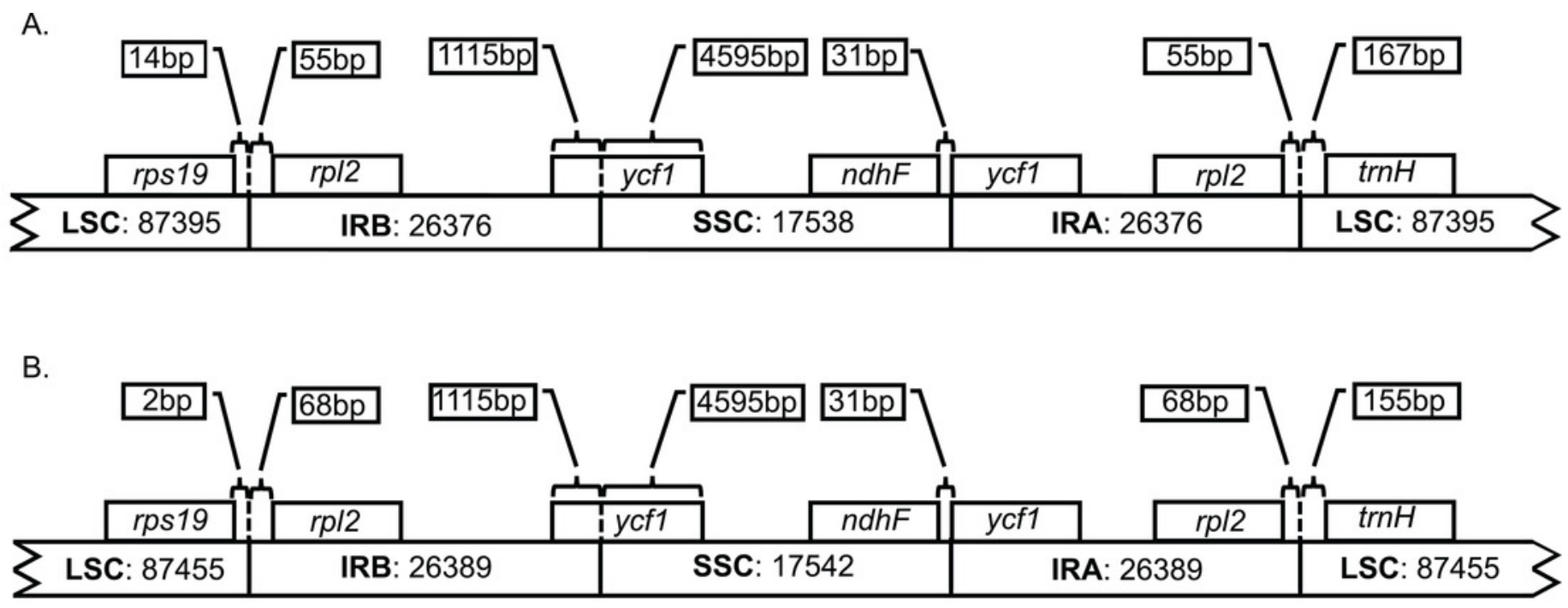
Figure 4

DNA polymorphism analysis of the plastid genome sequences of Brunellia antioquensis and $B$. trianae.

Nucleotide diversity $(\pi)$ evaluated with DnaSP6 (settings: window length: $600 \mathrm{bp}$, step size: $200 \mathrm{bp})$.

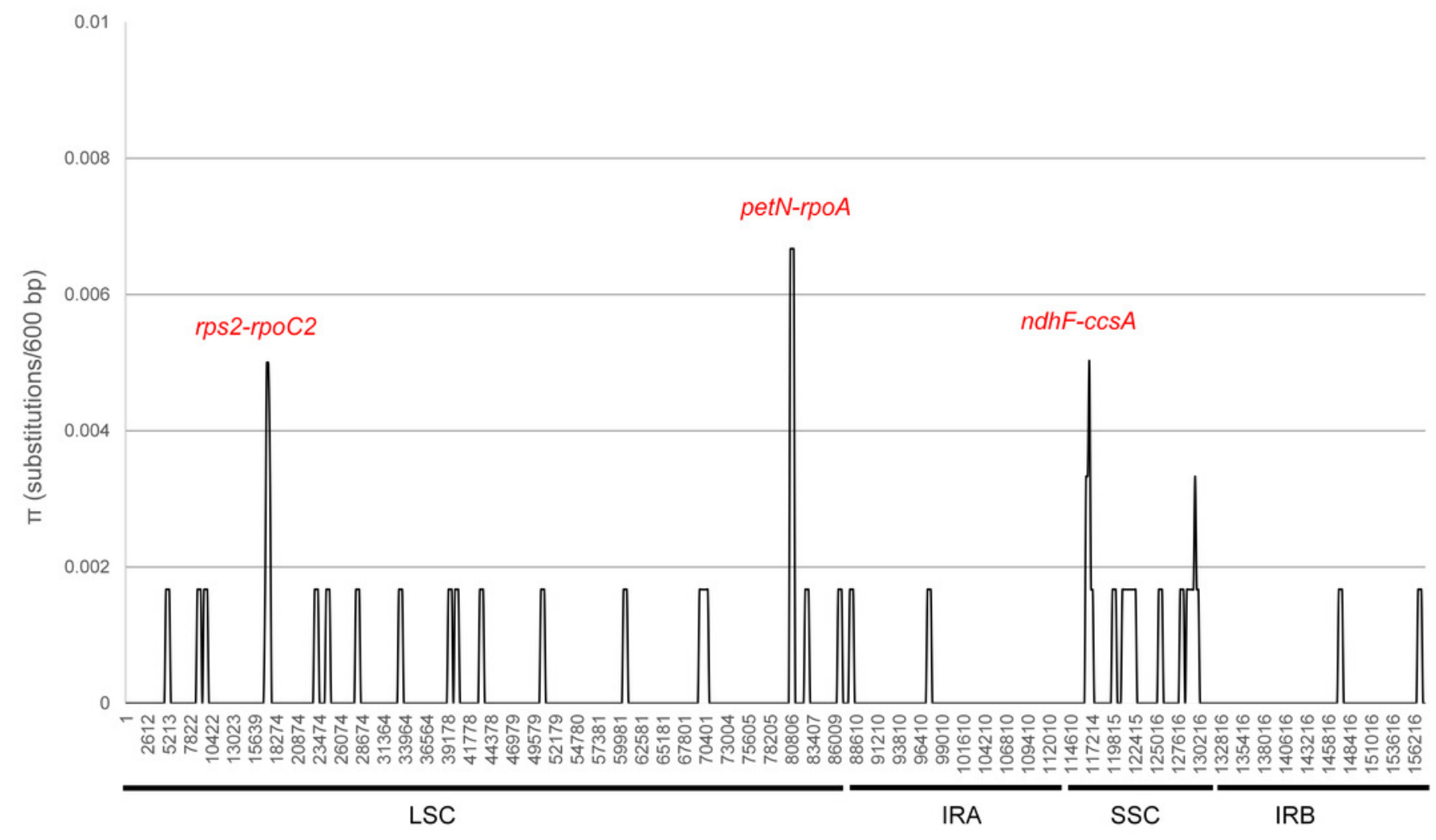


Figure 5

Phylogenetic relationships of 43 superrosid representatives.

Relationships inferred from the 75-plastid protein-coding regions using maximum likelihood (ML) analysis. Bootstrap values are $100 \%$ except where indicated.

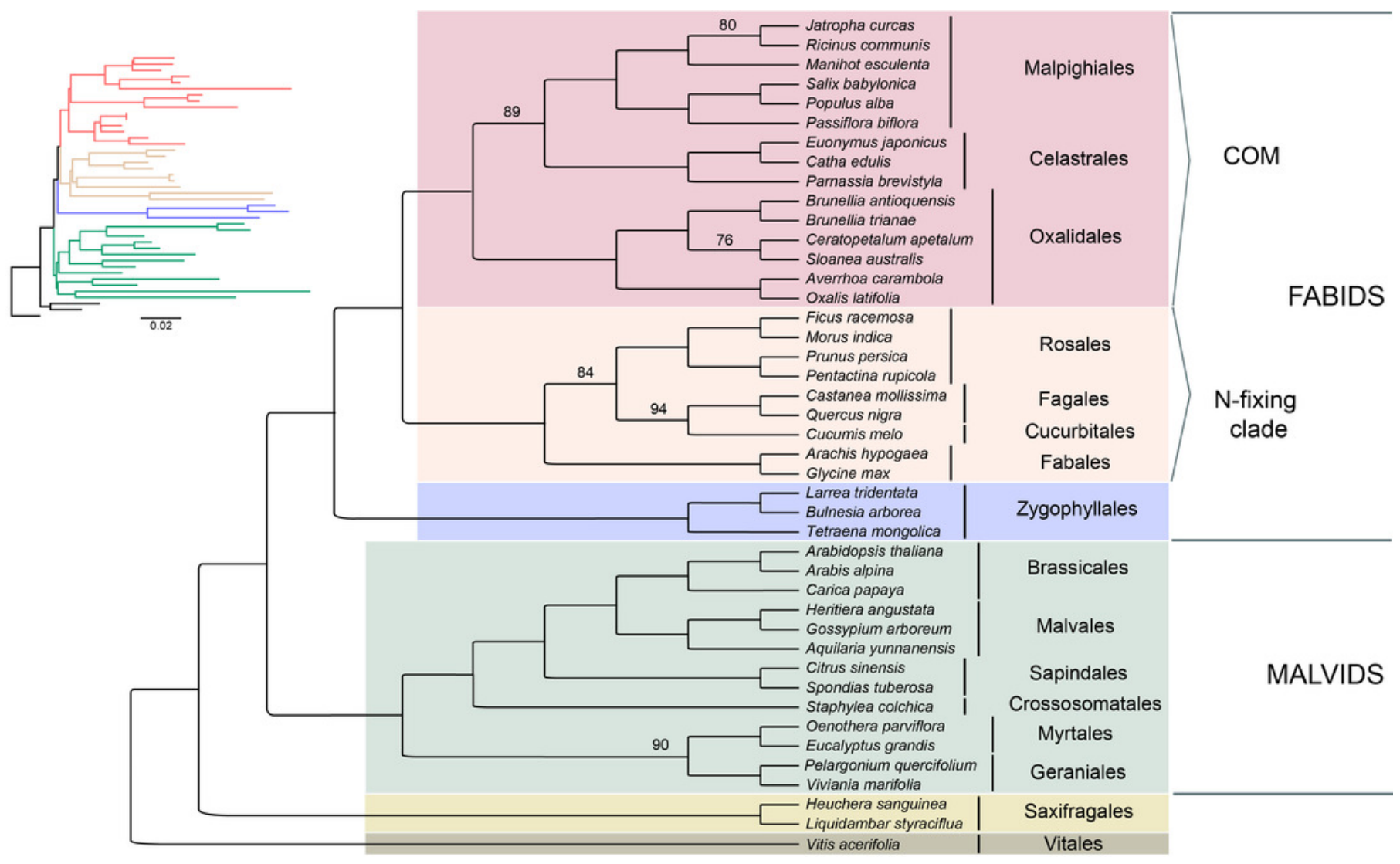


Table $\mathbf{1}$ (on next page)

Plastid genome characteristics of Brunellia antioquensis and B. trianae. 
1 Table 1. Plastid genome characteristics of Brunellia antioquensis and B. trianae

\begin{tabular}{lcccccccc}
\hline & Size & & & & & & & \\
B. antioquensis & $(\mathrm{bp})$ & Length (\%) & A (\%) & C (\%) & G (\%) & T (\%) & C/G (\%) & A/T (\%) \\
LSC & 87,395 & 55.42 & 31.90 & 17.9 & 17 & 33.3 & 34.85 & 65.15 \\
IRB & 26,376 & 16.73 & 28.7 & 20.6 & 22.2 & 28.6 & 42.75 & 57.25 \\
SCC & 17,538 & 11.12 & 34.4 & 15.0 & 16.2 & 34.4 & 31.22 & 68.78 \\
IRA & 26,376 & 16.73 & 28.6 & 22.2 & 20.6 & 28.7 & 42.75 & 57.25 \\
\hline Total & 157,685 & 100 & 31.08 & 18.73 & 18.36 & 31.83 & 37.09 & 62.91 \\
\hline B. trianae & & & & & & & & \\
LSC & 87,455 & 55.43 & 31.91 & 17.86 & 16.98 & 33.25 & 34.84 & 65.16 \\
IRB & 26,389 & 16.73 & 28.7 & 20.6 & 22.2 & 28.6 & 42.75 & 57.25 \\
SCC & 17,542 & 11.11 & 34.4 & 15 & 16.2 & 34.4 & 31.23 & 68.77 \\
IRA & 26,389 & 16.73 & 28.6 & 22.2 & 20.64 & 28.7 & 42.75 & 57.25 \\
\hline Total & 157,775 & 100 & 31.08 & 18.72 & 18.36 & 31.83 & 37.09 & 62.91 \\
\hline
\end{tabular}

2

3

4 